\title{
Some studies on cutting force and temperature in machining Ti-6Al-4V alloy using regression analysis and ANOVA
}

\author{
Ramanuj Kumar $^{a^{*}}$, Ashok Kumar Sahoo ${ }^{a}$, K.Satyanarayana ${ }^{b}$ and G. Venkateswara Rao ${ }^{\text {b }}$
}

${ }^{a}$ School of Mechanical Engineering, KIIT University, Bhubaneswar-24, India

${ }^{b}$ Department of Mechanical Engineering, NIT, Warangal-506004, India

C H R O N I L E A B T T A C T

Article history:

Received January 32013

Received in revised format

March 92013

Accepted March 102013

Available online

March 102013

Keywords:

Cutting force

Cutting temperature

ANOVA

Regression

\section{Introduction}

Titanium alloys are extensively used in aerospace, power industries and gas turbine engines. Most of the components of titanium are manufactured by traditional machining techniques such as turning, milling, drilling, reaming and grinding etc. The machinability titanium alloy is poor owing to several inherent properties. Titanium and titanium alloys have low thermal conductivity and high chemical reactivity with many cutting tool materials. Its low thermal conductivity increases the temperature at the cutting edge of the tool. Hence, on machining, the cutting tools wear off very rapidly due to high cutting temperature and strong adhesion between tool and workpiece material. Machining of titanium alloys at higher cutting speed will cause rapid chipping at the cutting edge, which leads to catastrophic failure of the inserts. Therefore proper selections of process parameters are highly essential for effective machining operations.

\footnotetext{
* Corresponding author.

E-mail: ramanujkumar22@gmail.com m (R. Kumar)

(C) 2013 Growing Science Ltd. All rights reserved.

doi: $10.5267 / j$. .jiec.2013.03.002
} 
Kosaraju et al. (2012) investigated the effect of process parameters on machinability performance characteristics of Titanium using Taguchi Technique. Cutting speed was identified as the most influential process parameter on cutting force and temperature. Davim (2001) studied the influence of cutting conditions on the surface finish in turning using carbide tool based on Taguchi method and established a correlation between cutting parameters with roughness using multiple linear regression analysis. The results indicated that the cutting speed and interaction between cutting speed/feed had a greater influence on surface roughness followed be feed. Depth of cut did not have significance. Dabnun et al. (2005) developed response surface model for surface roughness utilizing factorial DOE and response surface methodology during machinability studies of glass ceramic using uncoated carbide inserts under dry cutting conditions. Feed rate was the main influencing factor on the roughness, followed by the cutting speed and depth of cut. Arbizu and Luis Pérez (2003) developed surface roughness model using RSM. Feed and depth of cut were the factors that influenced the surface roughness.

Singh and Kumar (2006) found that the percent contributions of depth of cut (55.15\%) and feed rate (23.33 \%) affecting the feed force was significantly larger as compared to the contribution of the cutting speed (2.63 \%) when machining EN24 steel with TiC-coated tungsten carbide inserts using Taguchi's design approach. Sahoo and Sahoo (2012) studied the machinability studies on flank wear, surface roughness, chip morphology and cutting forces in finish hard turning of AISI 4340 steel using uncoated and multilayer TiN and $\mathrm{ZrCN}$ coated carbide inserts at higher cutting speed range. The process has also been justified economically for its effective application in hard turning.

Ali $\mathrm{MH}$ et al. (2012) presented the prediction of the cost of manufacturing in terms of tool life and machining time saving by using finite-element modeling in machining titanium alloy Ti-6Al-4V. The cutting process of Ti-6Al-4V was simulated using orthogonal cutting finite element model. The workpiece and tool have been designed and presented in a two-dimensional fully thermo-mechanically coupled and define all the parameters into the ABAQUS/EXPLICIT finite-element software. The cemented carbide cutting tool is used for the simulation. Vijay Sekar and Pradeep Kumar (2011) assessed the performance of four material model sets of the Johnson-Cook (JC) constitutive equation in modeling the deformation behavior of Ti6Al4V alloy. The FE code relied on the qualitative nature of inputs such as material flow stress model, friction conditions, fracture criterions and the accuracy of the modeling process. The FE output at steady state conditions was compared with results from orthogonal cutting experiments on a tube of the work material. The effect of the parameters of the JC law and the capabilities of the constitutive equation were analyzed. It was revealed that the used FE model was excellent in predicting the effective stress, strain and temperature, but produced marginal deviations in cutting force and chip morphology predictions. The material model constants computed through an evolutionary computational optimization process and those with conditions similar to machining produced good correlation with experiments.

Ozel and Zeren (2006) presented a methodology to determine flow stress at the machining regimes and friction characteristics at the tool-chip interface from the results of orthogonal cutting tests. This also evaluated several temperature models in calculating the average temperatures at primary and secondary deformation zones and present comparisons with the experimental data obtained for AISI 1045 steel through assessment of machining models (AMM) activity. The proposed methodology was utilized to measured forces and chip thickness obtained through a basic orthogonal cutting test. This conveniently determined the work material flow stress at the primary deformation zone and the interfacial friction characteristics along the tool rake face. This explained a methodology to extend the applicability of a Johnson-Cook work material model to machining regimes. Iqbal et al. (2009) developed the experimental setup and finite element modeling of dry sliding of metals to estimate interface heat transfer coefficient. Heat transfer between the chip, the tool, and the environment during the metal machining process has an impact on temperatures, wear mechanisms and hence on tool-life and on the accuracy of the machined component. For modeling of the metal machining process, the interface heat 
transfer coefficient is an important input parameter to quantify the transfer of heat between the chip and the tool and to accurately predict the temperature distribution within the cutting tool. An experimental setup was developed, in which an uncoated cemented carbide pin was rubbed against a steel workpiece while the later was rotated at speeds similar to the cutting tests. A FE model was constructed for heat generation and frictional contact. The experimental and modeling results of the dry sliding process yield the interface heat transfer coefficient for a range of rubbing speeds.

Sun et al. (2009) studied the chip formation during dry turning of Ti6Al4V alloy. It was examined in association with dynamic cutting force measurements under different cutting speeds, feed rates and depths of cut. Both continuous and segmented chip formation processes were observed. The cyclic force frequency increased linearly with cutting speed and decreased inversely with feed rate. The cutting force increased with the feed rate and depth of cut at constant cutting speed due to the large volume of material being removed. The increase in cutting force with increasing cutting speed was attributed to the strain rate hardening at low and high strain rates, respectively. The decrease in cutting force with increasing cutting speed outside these speed ranges was due to the thermal softening of the material.

Iqbal et al. (2008) discussed the effects of the interface heat transfer coefficient on the output of the finite element model of metal cutting process for a wide range of cutting speeds. An updated Lagrangian finite element code DEFORM 2D simulating continuous chip formation was used for the modeling of two dimensional orthogonal machining process. A sensitivity study was performed by varying interface heat transfer coefficient in the simulation of orthogonal cutting process. The effects of varying interface heat transfer coefficient on the simulation output: cutting forces, temperature, shear angle, and chip morphology was analyzed. The simulated results were also compared with the temperature measurement results of high cutting speed experiments. The comparison of simulation results showed that in finite element modeling of the machining process, temperature in tool and chip morphology were significantly influenced by selection of the interface heat transfer coefficient.

Upadhyay et al. (2012) utilized vibration signals for in-process prediction of surface roughness during turning of Ti-6Al-4V alloy. First order and second order multiple regression models using only vibration signals were developed and based on $\mathrm{R}^{2}$ value and maximum percentage error neither of the two was found to have satisfactory prediction ability. Consequently, Pearson correlation coefficient was used to determine the correlation between surface roughness and cutting parameters and acceleration amplitude of vibrations. Based on Pearson correlation coefficient multiple regression model was developed using above mentioned input parameters. As this model was found accurate enough, neural network model was developed using the same combination of input parameters. Thus, the use of in-process surface roughness prediction can provide an opportunity to take in time corrective action to control the surface finish within required limits.

Sahoo and Sahoo (2012) presented the mathematical modeling and parametric optimization on flank wear and surface roughness based on response surface methodology and grey-based Taguchi method in finish hard turning of AISI 4340 steel using multilayer coated carbide (TiN/TiCN/ $\mathrm{Al}_{2} \mathrm{O}_{3} / \mathrm{TiN}$ ) insert under dry environment. The economical feasibility of utilizing multilayer TiN coated carbide insert was described. Model adequacy was checked using correlation coefficients. Jangra et al. (2011) proved the potential of GRA along with Taguchi method to optimize process parameters for multi-machining characteristics in wire electrical discharge machining of WC-Co composite. Sahoo and Sahoo (2011) developed the mathematical model and parametric optimization for surface roughness in turning D2 steel using TiN coated carbide insert using Taguchi parameter design and response surface methodology. Good correlation between the RSM model predicted values and experimental values exist at 95\% confidence intervals and found to be adequate. Kumar et al. (2013) conducted machining of titanium alloys and developed the analytical method to find the convection coefficient and interface 
heat transfer coefficients at tool tip-workpiece interface. The experimental and simulated results were compared and validated.

The objectives of present work deals with the study of the effect of cutting speed and feed rate on the components of force and temperature during turning of titanium alloys Ti-6Al-4V using TiN coated carbide inserts under dry environment. The mathematical model and parametric optimization study has also been carried out.

\section{Experimental methodology}

Experiments have been carried out in dry machining on the MAGNUM MA-1430 lathe. The workpiece material used is Ti6Al4V bar (Grade 5). Ti-6Al-4V offers a combination of high strength, light weight, formability and corrosion resistance which has made it attractive in aerospace applications. The tool material used in the experimental work was PVD TiN coated carbide inserts designated as CNMG120408AP along with the tool holder PCLNR 2020 K12 (Tool geometry: approach angle: 950, rake angle: $-5^{0}$ and inclination angle: $-7^{0}$ ). Experiments have been conducted with cutting speeds (v) of 45, 60, $75 \mathrm{~m} / \mathrm{min}$, feed (f) of $0.25,0.3,0.35 \mathrm{~mm} / \mathrm{rev}$ with constant depth of cut of $0.5 \mathrm{~mm}$. Nine sets of data have been selected for the experimental tests. Initially, the specimens were turned with $0.5 \mathrm{~mm}$ cutting depth in order to remove the outer layer. The forces generated during machining i.e. axial force (Fx), radial force (Fy) and tangential force $(\mathrm{Fz})$ were measured by piezoelectric dynamometer (Kistler, 9272). The resultant cutting force (F) was computed. The cutting temperature (T) was measured using infrared temperature measuring equipment (Kiray 300) for every pass at the interface of tool tip and workpiece. The cutting conditions and experimental results are furnished in Table 1 and 2.

\section{Table 1}

Cutting conditions

\begin{tabular}{ll}
\hline Cutting conditions & Descriptions \\
\hline Workpiece & Ti6Al4V \\
Cutting tool & PVD TiN coated carbide \\
Tool geometry & CNMG120408AP \\
Tool holder & PCLNR2020K12 \\
Cutting speed, $\mathrm{v}(\mathrm{m} / \mathrm{min})$ & $45,60,75$ \\
Feed, $\mathrm{f}(\mathrm{mm} / \mathrm{rev})$ & $0.25,0.3,0.35$ \\
Depth of cut, d $(\mathrm{mm})$ & 0.5 \\
Cutting environment & Dry \\
Responses & Cutting force, cutting temperature \\
\hline
\end{tabular}

Table 2

Experimental results

\begin{tabular}{cclccccc}
\hline No. & v & f & $\begin{array}{c}\text { Axial force, } \\
\text { Fx (N) }\end{array}$ & $\begin{array}{c}\text { Radial force, } \\
\text { Fy (N) }\end{array}$ & $\begin{array}{c}\text { Tangential force, } \\
\text { Fz (N) }\end{array}$ & $\begin{array}{c}\text { Resultant cutting } \\
\text { force, F (N) }\end{array}$ & $\begin{array}{c}\text { Cutting } \\
\text { temperature, }\left({ }^{0} \mathrm{C}\right)\end{array}$ \\
\hline 1 & 45 & 0.25 & 132 & 88 & 445 & 472 & 188 \\
2 & 45 & 0.3 & 137 & 92 & 453 & 482 & 197 \\
3 & 45 & 0.35 & 145 & 98 & 479 & 510 & 209 \\
4 & 60 & 0.25 & 126 & 84 & 426 & 452 & 192 \\
5 & 60 & 0.3 & 132 & 86 & 442 & 469 & 204 \\
6 & 60 & 0.35 & 139 & 95 & 463 & 493 & 216 \\
7 & 75 & 0.25 & 118 & 80 & 395 & 421 & 198 \\
8 & 75 & 0.3 & 125 & 84 & 414 & 441 & 210 \\
9 & 75 & 0.35 & 131 & 92 & 425 & 454 & 225 \\
\hline
\end{tabular}




\section{Results and discussions}

\subsection{Development of mathematical model}

The output dependent variables such as resultant cutting force $(\mathrm{F})$ and cutting temperature $(\mathrm{T})$ can be related as a linear function of independent variables i.e. cutting speed (v) and feed (f). The correlation between them is given by (Thangavel \& Selladurai, 2008).

$F=k_{o}+k_{1} v+k_{2} f$,

where ko is the free term of the regression equation and the coefficients $\mathrm{k} 1$ and $\mathrm{k} 2$ are linear terms respectively. When a multiple linear regression analysis is employed applying least square method, the following equations are obtained in uncoded units as.

$$
\begin{aligned}
\mathrm{F}= & 452.667-1.644 \mathrm{v}+373.333 \mathrm{f} \\
& \left(\mathrm{R}^{2}=96.4 \%, \mathrm{R}^{2}(\operatorname{adj})=95.2 \%\right) \\
\mathrm{T}= & 106.333+0.433 \mathrm{v}+240 \mathrm{f} \\
& \left(\mathrm{R}^{2}=98.9 \%, \mathrm{R}^{2}(\operatorname{adj})=98.5 \%\right)
\end{aligned}
$$

The significance test of the regression model and significance on individual model coefficients were performed to verify the goodness of fit for the obtained mathematical model. The analysis of variance (ANOVA) is usually applied to verify the significance of model developed (Singh \& Rao, 2007). This analysis is done at a confidence level of $95 \%$ or significance level of $5 \%$ which is shown in Table 3 and Table 4 . When the $\mathrm{P}$ value for the term is less than 0.05 and calculated F-ratio is more than standard tabulated value, the models are said to be statistically significant. From the ANOVA table, it is revealed that, both the developed models are significant and the terms in the model have the significant effect on the cutting force and temperature.

Table 3

ANOVA table of $1^{\text {st }}$ order model for cutting force $(\mathrm{F})$

\begin{tabular}{lccccccc}
\hline Source & DF & Seq SS & Adj SS & Adj MS & F & P value & Remarks \\
\hline Regression & 2 & 5741.33 & 5741.33 & 2870.67 & 80.24 & 0.000 & Significant \\
Residual Error & 6 & 214.67 & 214.67 & 35.78 & & & \\
\hline Total & 8 & 5956 & & & & & \\
\hline
\end{tabular}

\section{Table 4}

ANOVA table of $1^{\text {st }}$ order model for cutting temperature $(\mathrm{T})$

\begin{tabular}{lccccccc}
\hline Source & DF & Seq SS & Adj SS & Adj MS & F & P value & Remarks \\
\hline Regression & 2 & 1117.5 & 1117.5 & 558.75 & 268.2 & 0.000 & Significant \\
Residual Error & 6 & 12.5 & 12.5 & 2.083 & & & \\
\hline Total & 8 & 1130 & & & & & \\
\hline
\end{tabular}

Other important coefficient, $\mathrm{R}^{2}$, called determination coefficients is also analyzed for the degree of fit. More the value of $\mathrm{R}^{2}$ (approaches to one), better the mathematical model fits the actual data and residuals are less. The developed mathematical model presented high correlation coefficient $\left(\mathrm{R}^{2}=\right.$ 0.964 and 0.989 ) explaining $96.4 \%$ and $98.9 \%$ of the variability in the cutting force and cutting temperature respectively. It indicates that the model is predicted better for responses. Furthermore, the $\mathrm{R}^{2}$ and adjusted $\mathrm{R}^{2}$ values are very close and does not differ so much (Lalwani et al., 2008). It concludes that irrelevant terms are not involved in the model and a good correlation exists between the experimental and predicted values. 
Also, from Anderson-Darling test for cutting force and cutting temperature (Fig. 1-2), the data closely follows the straight line and $\mathrm{P}$ value is greater than 0.05 at $95 \%$ confidence level. It signifies that the data follow a normal distribution and the model developed by Eq 2-3 is suitable and quite adequate. The residuals fall on a straight line from normal probability plots (Figs. 3-4) suggesting that the errors are distributed normally and the terms mentioned in the model are significant. Also, from Fig. 5-6 (residuals vs. fitted value), no unusual structure is found. From Fig. 7-8 (residual vs. order of data), it is revealed that the residuals are random in nature and don't exhibit any pattern with run order. Thus, the developed mathematical models can be effectively utilized for prediction of cutting force and cutting temperature in turning.

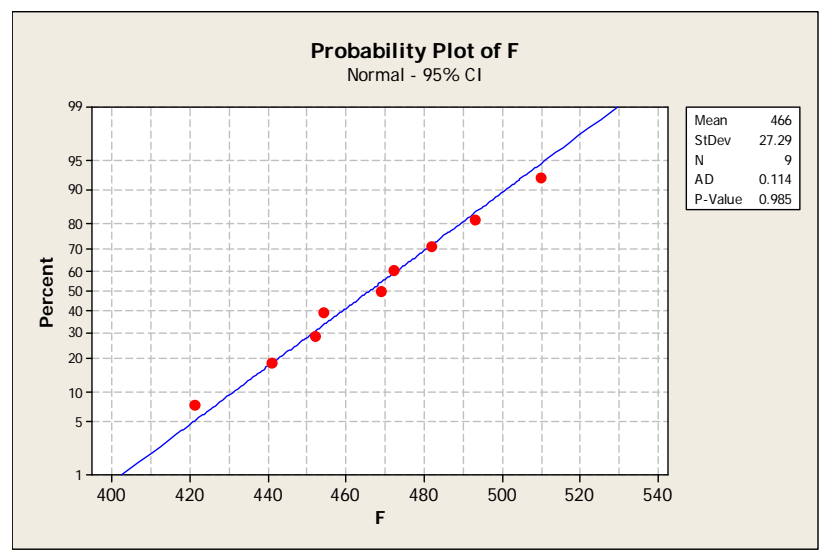

Fig. 1. Anderson Darling test for normality for cutting force (F)

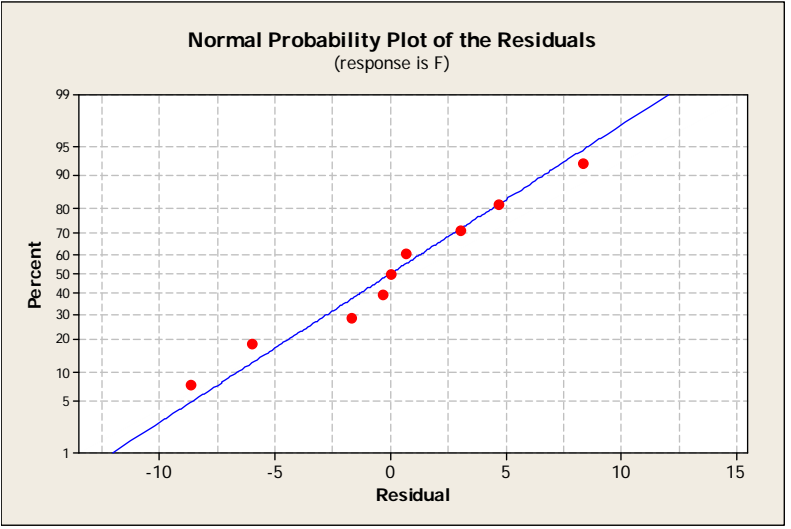

Fig. 3. Normal probability plot of residuals for cutting force (F)

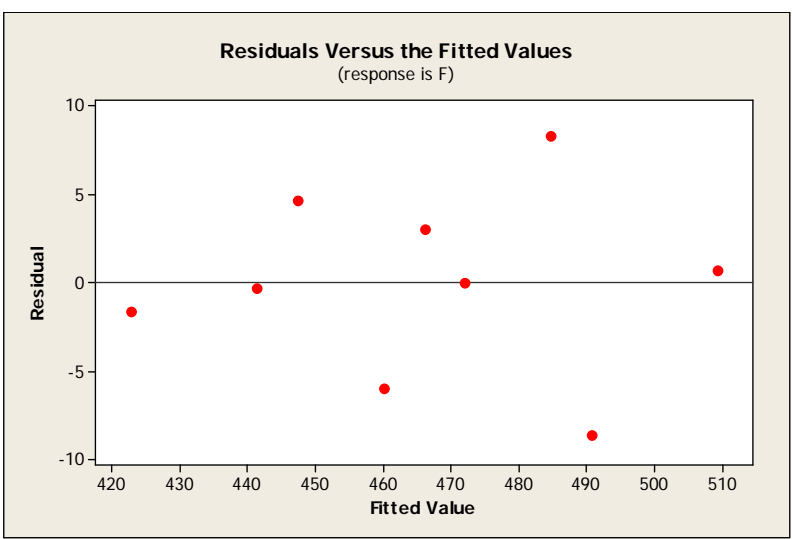

Fig. 5. Residuals vs. fitted values for cutting force (F)

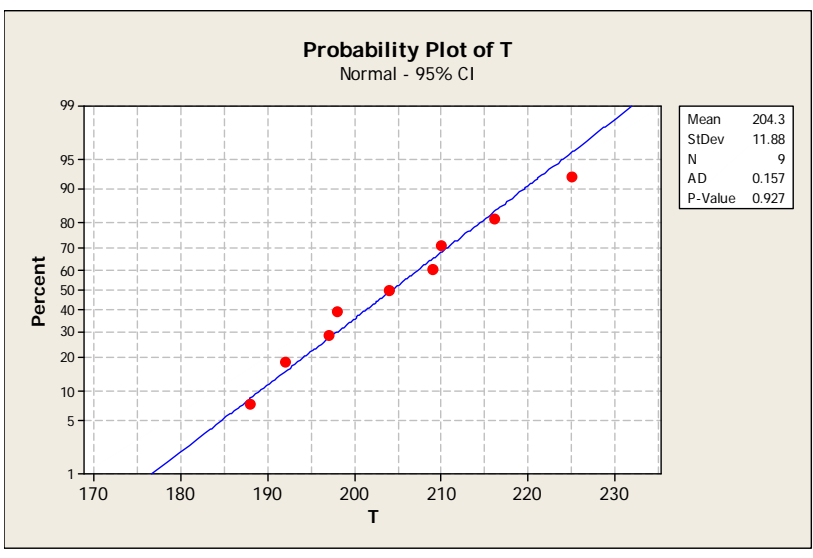

Fig. 2. Anderson Darling test for normality for cutting temperature $(\mathrm{T})$

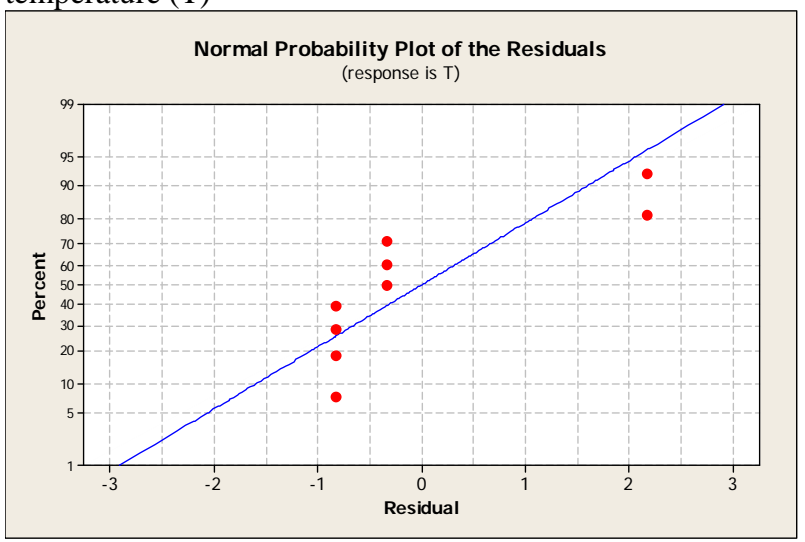

Fig. 4. Normal probability plot of residuals for cutting temperature (T)

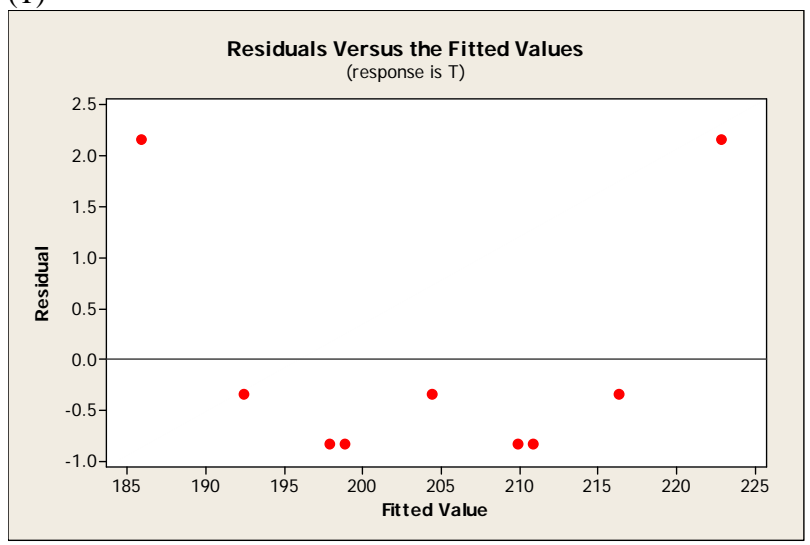

Fig. 6. Residuals vs. fitted values for cutting temperature (T) 


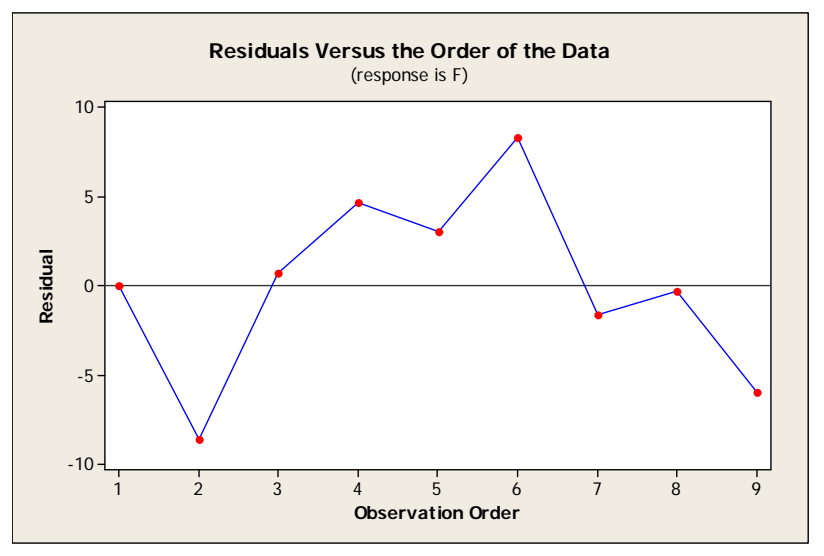

Fig. 7. Residuals vs. order of the data for cutting force (F)

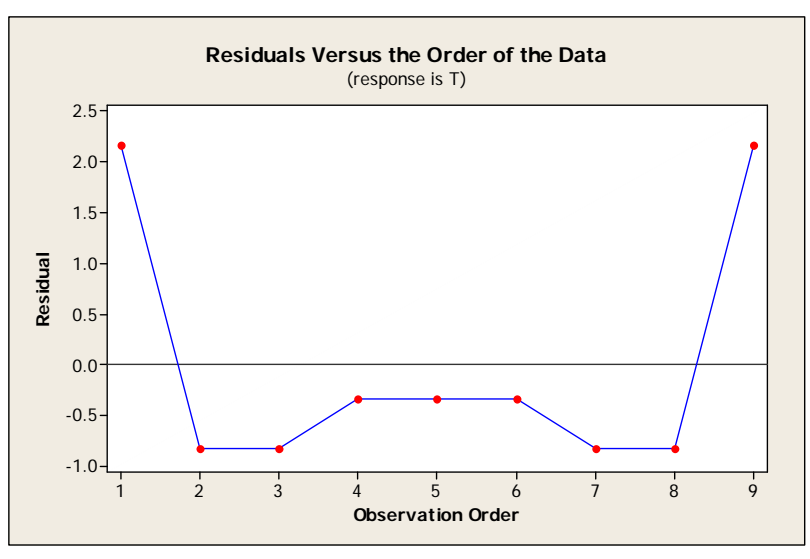

Fig. 8. Residuals vs. order of the data for cutting temperature $(\mathrm{T})$

For validation of models, some confirmation experiments were conducted using three new sets of process parameters (1c, 2c and 3c) shown in Table 5.

\section{Table 5}

Comparison of results obtained from experiment with model

\begin{tabular}{lllllllll}
\hline Test & \multicolumn{2}{l}{ Process parameters } & \multicolumn{2}{l}{ Experiment } & \multicolumn{2}{l}{ Model } & \multicolumn{2}{l}{ Error (\%) } \\
\hline & $\mathrm{V}$ & $\mathrm{f}$ & $\mathrm{F}$ & $\mathrm{T}$ & $\mathrm{F}$ & $\mathrm{T}$ & $\mathrm{F}$ & $\mathrm{T}$ \\
\hline 1c & 50 & 0.25 & 468 & 192 & 464 & 188 & 0.85 & 2.08 \\
2c & 70 & 0.3 & 445 & 206 & 450 & 209 & -1.12 & -1.45 \\
3c & 90 & 0.35 & 430 & 238 & 435 & 229 & -1.16 & 3.78 \\
\hline
\end{tabular}

Table 5 shows the comparison of cutting force and cutting temperature between the experimental value and model value. The calculated error for cutting force lies between -1.12 to $0.85 \%$ and for cutting temperature, error lies between -1.45 to $3.78 \%$ respectively. Thus, the developed mathematical model can be used to predict the cutting force and cutting temperature within the limits of the factors studied with good degree of approximation.

\subsection{Parametric optimization}

The optimal parametric combination for both cutting force and temperature are obtained from the study of contour plots (Figs. 9-10). From the cutting speed-feed plane, it is evident that the lower cutting force can be achieved when cutting speed is at highest level $(\mathrm{m} / \mathrm{min})$ and feed is at lowest level $(\mathrm{mm} / \mathrm{rev})$ and the optimal parametric combination for lowest cutting force is $\mathrm{v} 3(75 \mathrm{~m} / \mathrm{min})-\mathrm{f} 1(0.25$ $\mathrm{mm} / \mathrm{rev}$ ). Similarly, the optimal parametric combination for minimum cutting temperature is $\mathrm{v} 1$ (45 $\mathrm{m} / \mathrm{min})$ - f $1(0.25 \mathrm{~mm} / \mathrm{rev})$.

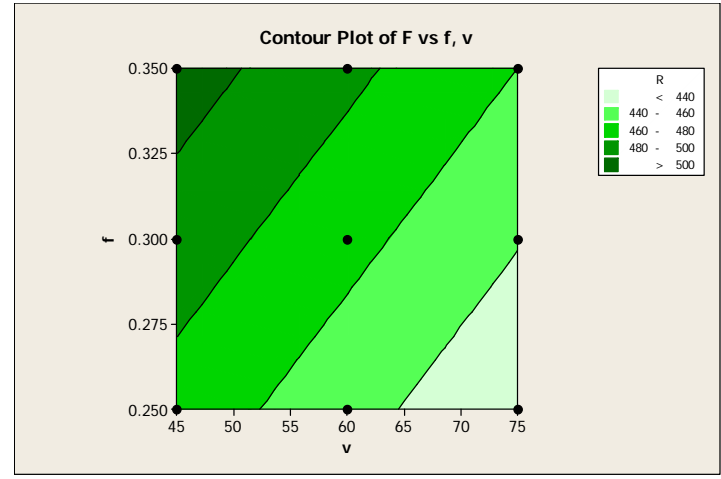

Fig. 9. Contour plot of F vs. v and $f$

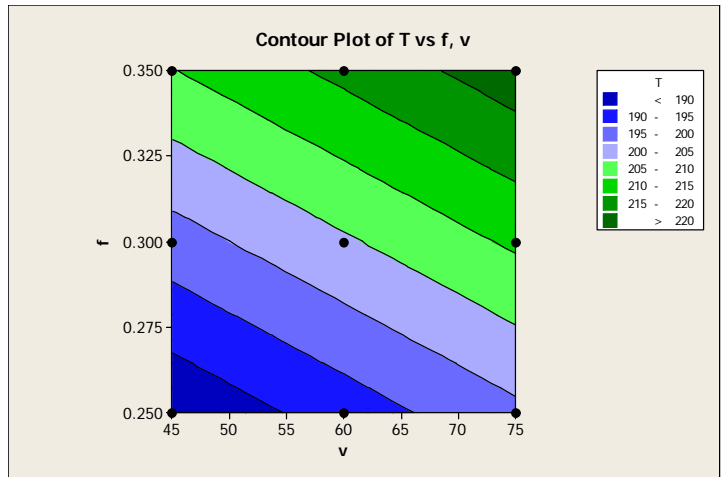

Fig. 10. Contour plot of $\mathrm{T}$ vs. $\mathrm{v}$ and $\mathrm{f}$ 


\subsection{Effect of process parameters}

The effect of process parameters on cutting force and temperature have been studied with the help of main effect plot and analysis of variance. ANOVA analysis tells about the significance of process parameter influencing the responses. The F-test has been carried out at $95 \%$ confidence level. F-value is the ratio of mean square deviations of each parameter to the mean square error. If calculated F-value is greater than F-table value, the parameter is said to be statistically significant. Also if probability of significance (P-value) is less than 0.05 at $95 \%$ confidence level, then the factors are said to be statistical significance on responses (Haron et al., 2007).

Table 6 and Table 7 show the results of ANOVA for cutting force and cutting temperature respectively. From Table 6 and Table 7, it is apparent that, the P-values for all the process parameters are less than 0.05 calculated value of $\mathrm{F}$ is more than $\mathrm{F}$ table value at $95 \%$ confidence levels. However, cutting speed is found to be the most significance parameter on cutting forces followed by feed. Similarly, for cutting temperature, feed is found to be the most influencing parameter followed by cutting speed. This trend has also been observed from the main effect plot also (Figs. 11-12). The decreasing trend of cutting force is noticed when the cutting speed is elevated (Fig. 11). At higher cutting speed, cutting temperature is high enough to soften the work material and reduces material shear strength (More et al., 2006). This leads to the evolution of less magnitude of cutting forces at higher cutting speeds during machining titanium alloys.

\section{Table 6}

Results of ANOVA for cutting force (F)

\begin{tabular}{cccccccc}
\hline Source & DF & Seq SS & Adj SS & Adj MS & F & P & Remarks \\
\hline v & 2 & 3778.7 & 3778.7 & 1889.3 & 110.06 & 0.000 & Significant \\
$\mathrm{f}$ & 2 & 2108.7 & 2108.7 & 1054.3 & 61.42 & 0.001 & Significant \\
Error & 4 & 68.7 & 68.7 & 17.2 & & & \\
\hline Total & 8 & 5956 & \multicolumn{7}{c}{} \\
\hline
\end{tabular}

Table 7

Results of ANOVA for cutting temperature (T)

\begin{tabular}{cccccccc}
\hline Source & DF & Seq SS & Adj SS & Adj MS & F & P & Remarks \\
\hline $\mathrm{v}$ & 2 & 254 & 254 & 127 & 50.8 & 0.001 & Significant \\
$\mathrm{f}$ & 2 & 866 & 866 & 433 & 173.2 & 0.000 & Significant \\
Error & 4 & 10 & 10 & 2.5 & & & \\
\hline Total & 8 & 1130 & & & & & \\
\hline
\end{tabular}

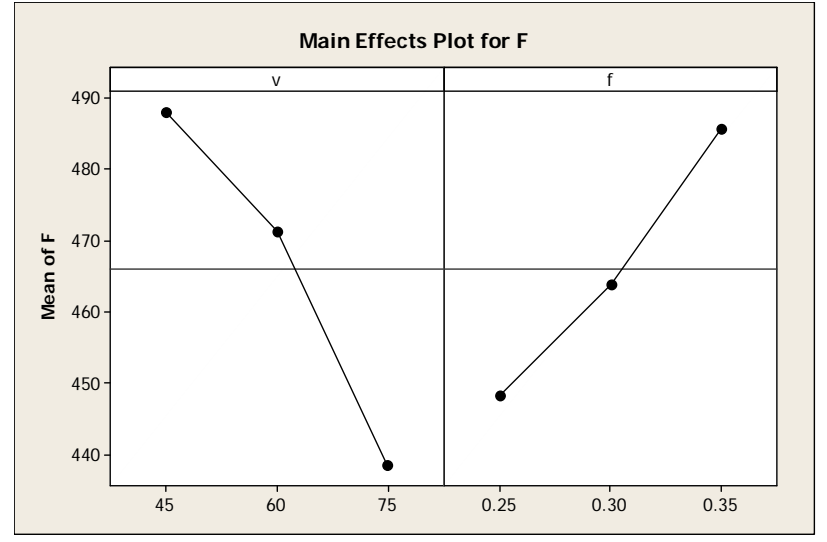

Fig. 11. Main effects plot for cutting force

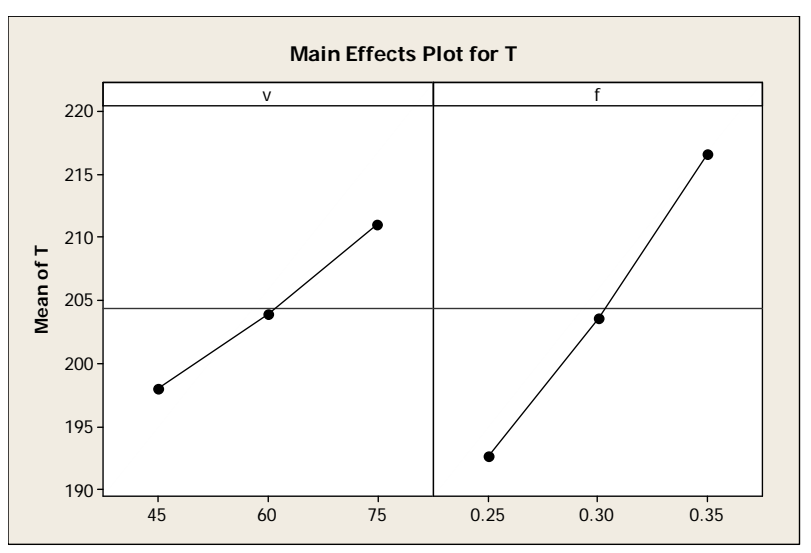

Fig. 12. Main effects plot for cutting temperature 


\section{Conclusions}

The study is based on the experimental investigation, development of mathematical models and parametric optimization in machining titanium alloy using PVD TiN coated carbide insert under dry environment. Therefore based from the findings of the research, following conclusions are drawn:

1. The investigation indicates that the process parameters i.e. cutting speed and feed are the influencing factors which affect the cutting force and temperature in machining. However, cutting speed is found to be the most significance parameter affecting cutting forces whereas feed is for cutting temperature at $95 \%$ confidence level.

2. The mathematical model presented high correlation coefficient $\left(\mathrm{R}^{2}=0.964\right.$ and 0.989 explaining $96.4 \%$ and $98.9 \%$ of the variability in the cutting force and temperature which indicates the goodness of fit for the model and high significance of the model.

3. The data closely follows the straight line observed from Anderson-Darling normality tests. Normal probability plot of models shows that the residuals fall on a straight line implying that errors are distributed normally. It indicates the goodness of fit for the model and high significance of the model.

4. The experimental and predicted values are fairly close to each other. The calculated error for cutting force lies between -1.16-0.85 \% and temperature lies between -1.45 - 3.78 percent respectively. The developed equations correlate the relationship of the cutting force and temperature with the process parameters with good degree of approximation and can be effectively utilized for prediction of responses in machining.

5. From the contour plots, the optimal parametric combination for lowest cutting force is found to be cutting speed of $75 \mathrm{~m} / \mathrm{min}$ and feed of $0.25 \mathrm{~mm} / \mathrm{rev}$.

6. From the contour plots, the optimal parametric combination for lowest temperature is found to be cutting speed of $45 \mathrm{~m} / \mathrm{min}$ and feed of $0.25 \mathrm{~mm} / \mathrm{rev}$.

\section{References}

Ali, M.H., Khidhir, B.A., Mohamed, B, \& Oshkour, A.A. (2012). Prediction of high cutting speed parameters for Ti-6Al-4V by using Finite Element Modeling. International Journal of Modeling and Optimization, 2 (1), 31-45.

Davim, J.P. (2001). A note on the determination of optimal cutting conditions for surface finish obtained in turning using Design of Experiment. Journal of Materials Processing Technology, 116, 305-308.

Che Haron, C. H., Ghani, J. A., \& Ibrahim, G. A. (2007). Surface integrity of AISI D2 when turned using coated and uncoated carbide tools. International Journal of Precision Technology, 1(1), 106114.

Iqbal, SA., Mativenga, PT. \& Sheikh, MA. (2008). A sensitivity study of the effects of interface heat transfer coefficient on FE modeling of machining process for a wide range of cutting speeds, The 6th international conference on manufacturing research, Brunel university, UK.

Iqbal, SA., Mativenga, PT., \& Sheikh, MA. (2009). An investigative study of the interface heat transfer coefficient for FE modeling of high speed machining. NED University Journal of Research, 6 (1), 44-56.

Jangra, K., Grover, S., \& Aggarwal, A. (2011). Simultaneous optimization of material removal rate and surface roughness for WEDM of WCCo composite using grey relational analysis along with Taguchi method. International Journal of Industrial Engineering Computations, 2, 479-490.

Kosaraju, S., Anne, VG., \& Popuri, BB. (2012). Taguchi analysis on cutting forces and temperature in turning titanium Ti-6Al-4V. International Journal of Mechanical and Industrial Engineering, 1 (4), 2231- 6477. 
Kumar, R., Sahoo, A.K., \& Kosaraju, S. (2013). Finite element simulation of forces and temperature in turning of titanium alloy using Deform 3D. International journal of mechanical engineering \& research, 3(5), 330-334.

Lalwani, DI., Mehta, NK. \& Jain, PK. (2008). Experimental investigations of cutting parameters influence on cutting forces and surface roughness in finish hard turning of MDN250 steel. Journal of Materials Processing Technology, 206 (1-3), 167-179.

Mohamed, A., Dabnun, M.S.J. Hashmi \& El-Baradie, MA. (2005). Surface roughness prediction model by design of experiments for turning machinable glass-ceramic (Macor). Journal of Materials Processing Technology, 164-165, 1289-1293.

More, AS., Jiang, W., Brown, WD. \& Malshe, AP. (2006). Tool wear and machining performance of cBN-TiN coated carbide inserts and PCBN compact inserts in turning AISI 4340 hardened steel. Journal of Materials Processing Technology, 180, 253-262.

Ozel, T., \& Zeren, E., (2006). A Methodology to determine work material flow stress and tool-chip interfacial properties by using analysis of machining. Journal of Manufacturing Science and Engineering, 128, 119-129.

Puertas Arbizu, I. \& Luis Pérez, CJ. (2003). Surface roughness prediction by factorial design of experiments in turning processes. Journal of Materials Processing Technology, 143-144, 390-396.

Sahoo, AK., \& Sahoo, B. (2012). Experimental investigations on machinability aspects in finish hard turning of AISI 4340 steel using uncoated and multilayer coated carbide inserts. Measurement, 45 (8), 2153-2165.

Sahoo, AK., \& Sahoo, B. (2012). Performance studies of multilayer hard surface coatings (TiN/TiCN/Al ${ }_{2} \mathrm{O}_{3} / \mathrm{TiN}$ ) of indexable carbide inserts in hard machining: Part-II (RSM, grey relational and techno economical approach), Measurement, http://dx.doi.org/10.1016/j.measurement.2012.09.023.

Sahoo, A.K. \& Sahoo, B. (2011). Surface roughness model and parametric optimization in finish turning using coated carbide insert: Response surface methodology and Taguchi approach. International Journal of Industrial Engineering Computations, 2, 819-830.

Singh, H., \& Kumar, P. (2006). Optimizing feed force for turned parts through the Taguchi Technique. Sadhana, 31 (6), 671-681.

Singh, D. \& Rao, PV. (2007). A surface roughness prediction model for hard turning process, International Journal of Advanced Manufacturing Technology, 32 (11-12), 1115-1124.

Sun, S., Brandt, M., \& Dargusch, MS. (2009). Characteristic of cutting forces and chip formation in cutting of titanium alloys, Internal Journal of machine tools \& manufacture, 49, 561-568.

Thangavel, P. \& Selladurai, V. (2008). An experimental investigation on the effect of turning parameters on surface roughness, International Journal of Manufacturing Research, 3 (3), 285-300.

Upadhyay, V., Jain, PK., \& Mehta, NK. (2012). In-process prediction of surface roughness in turning of Ti-6Al-4V alloy using cutting parameters and vibration signals, Measurement http://dx.doi.org/10.1016/j.measurement.2012.06.002.

Vijay Sekar, K. S., \& Pradeep Kumar, M. (2011). Finite element simulations of Ti6Al4V titanium alloy machining to assess material model parameters of the Johnson-Cook constitutive equation. Journal of the Brazilian Society of Mechanical Sciences and Engineering, 33(2), 203-211. 